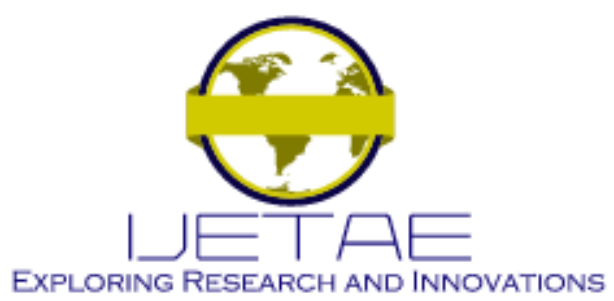

International Journal of Emerging Technology and Advanced Engineering

Website: www.ijetae.com (E-ISSN 2250-2459, Scopus Indexed, ISO 9001:2008 Certified Journal, Volume 11, Issue 11, November 2021)

Manuscript Received: 01 October 2021, Received in Revised form: 02 November 2021, Accepted: 06 November 2021

DOI: $10.46338 /$ ijetae1121_17

\title{
Hierarchical Fuzzy Signature and Neuro-Fuzzy Hybrid System for QMS Control
}

\author{
Raouf Ketata ${ }^{1}$, Hajer Ben Mahmoud ${ }^{2}$, Hela Lassoued ${ }^{3}$ \\ ${ }^{1,2,3}$ National Institute of Applied Science and Technology (INSAT) \\ ${ }^{1,3}$ Remote Sensing Laboratory and Spatial Reference Information Systems (LTSIRS) \\ ${ }^{2,3}$ Research Units on Computer Research Laboratory for Industrial Systems (LISI)
}

\begin{abstract}
Recently, the Quality Management System (QMS) control supports organizations managers identifying the best practices to upgrade the efficiency and effectiveness. This control has become a successful tool to improve the organization decision-making process. However, QMS encloses several performance indicators inputs that necessitate to be managed. In fact, it may include as inputs, customers requirements, quality policies, standard procedures and many other criteria. Hence, to provide the control of QMS problem insurance, two approaches are investigated which are Hierarchical Fuzzy Signature (HFS) and NeuroFuzzy Hierarchical Hybrid system (NFHH), respectively. These approaches are applied in the case of an industrial company operating in the electromechanical sector. This company has to be creative, agile, responsive and especially ready for fierce competition. Then, the obtained results are compared to Adaptive Neural Fuzzy Inference and Neural Network Systems, regarding the learning phase. Consequently, all of them help the company to assess its overall performance. However, NFHH reaches the best accuracy, reduces the number of neurons and uses the parameters that keep the universal approximated property of neural networks and fuzzy systems.
\end{abstract}

Keywords-Quality management system, Fuzzy logic, Neuro-Fuzzy, hierarchical structure, fuzzy signature.

\section{INTRODUCTION}

The multi-criteria approach for decision making problems profoundly insists on the precision and exact description of specific systems. Furthermore, the use of these approaches has to be justified for a well-defined system. However, when the complexity of the system increases, these approaches become insufficient and less efficient because they offer a severe aid on a strict interval [1]. In fact, for relatively complicated systems which enclose too many details and several criteria, the fuzzy logic was successfully applied for resolving their problems and challenges.
It is considered as a competitive concept in various fields including power regulating system [2], signal processing [3], quality control of food products [4], image processing [5] and many others

For the decision making process, fuzzy logic is also able to solve problems which include structured data and defined number of inputs [6,7]. Nevertheless, recent researchers deal with high dimensional data. Hence, the concept of fuzzy signature is innovated, especially for medical decision support systems [8].

Otherwise, the neural networks (NN) have been applied in multiple decision making processes, namely the budget allocation [11], the modelling heterogeneous patients [12], the detection and classification of defects [9] and the fault diagnosis [10].

However, the NN are not able to link digital data to linguistic one in classification tasks. Consequently, hybrid structure between fuzzy logic and $\mathrm{NN}$ is investigated in a Neuro-Fuzzy architecture. This structure is major in handling qualitative and quantitative inputs data [13].

For example, the heterogeneous input data which are treated in QMS control have to be managed by effective and robust structures. This subject is still studied to ensure the continuous improvement of organisations processes. On this basis, hybrid approaches are applied in this paper, to provide the control of QMS problem insurance. They are Hierarchical Fuzzy Signature (HFS) and Neuro-Fuzzy Hierarchical Hybrid system (NFHH).

This paper includes five sections as follows. Section 2 defines the problem. Section 3 details the two proposed approaches. Section 4 deals with the investigation of the two hybrid approaches to the case of an industrial company. Finally, in order to evaluate the obtained results in the learning phase, a comparative study between NFHH, Adaptive Neural Fuzzy Inference Systems (ANFIS) and $\mathrm{NN}$ is done. 


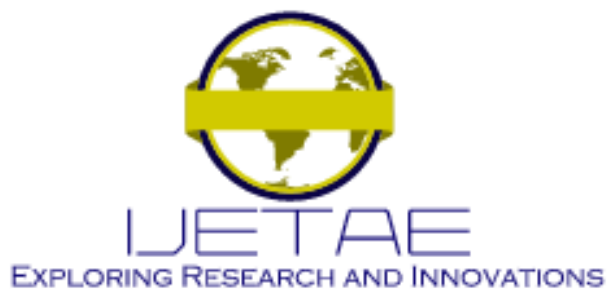

International Journal of Emerging Technology and Advanced Engineering

Website: www.ijetae.com (E-ISSN 2250-2459, Scopus Indexed, ISO 9001:2008 Certified Journal, Volume 11, Issue 11, November 2021)

\section{PROBLEM Formulation}

Based on International Standards Organization series ISO 9001, Figure 1 shows the continual improvement of the QMS which is composed of four processes i.e. Management responsibility, Resource management, Product realization and Improvement process. The inputs of this system are the customer's requirements for the product realization process, the expectations for the direction process and the measuring customer satisfaction for the improvement process.

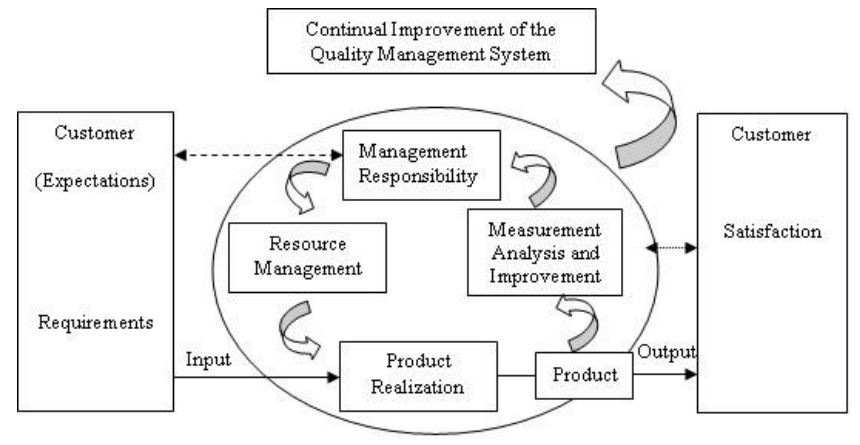

FIGURE 1.QMS MODEL (ISO 9001).

In recent years, the QMS control has become a strategic consideration for companies' businesses. Some companies aim to increase their productivity and to improve the effectiveness and efficiency of their systems. Hence, the complexity of QMS control is managed from a multitude of quantitative and qualitative objectives $\mathrm{OBJ}_{\mathrm{i}}(\mathrm{i}=1, \ldots, \mathrm{n})$ which are composed of a set of imprecise performance indicators inputs $\mathrm{IP}_{\mathrm{i}, \mathrm{j}}(\mathrm{i}=1, \ldots, \mathrm{n}$ et $\mathrm{j}=1, \ldots, \mathrm{m})$. All these indicators have to be handled. Therefore, in this paper, we present fuzzy hierarchical hybrid approaches that are able to ensure the control of QMS problems.

\section{HIERARCHICAL APPROACHES For QMS CONTROL}

Resolution of multi-criteria problems which ensure a large number of variables is considered as effectual by the use of hierarchical structures [11].Their advantage consists of the treatment of quantitative and qualitative variables. Therefore, hierarchical forms have been useful in classification issues which are similar to QMS control. In this subject, the purpose of this study is to apply Hierarchical Fuzzy Signature (HFS) and Neuro-Fuzzy (NFHH) approaches. They are mainly used in a QMS control problem which contains fuzzy, large, and diverse performance indicators inputs.

\section{A. Hierarchical Fuzzy Signature}

The signature concept has been used in various applications such as: clustering dynamic measurements [14], storage in electronic archives [15] and managing a library of reference software [16]. HFS with its hierarchical structure deals with the tasks ensuring diverse inputs. Therefore, decision-making experts' problems could be resolved by applying HFS, especially for classification or comparison of multiple cases and/or missing elements. The advantage of this concept is to manage complex problems with many diverse variables [17]. Indeed, HFS categories interdependent variables into sub-groups that determine the result in the upper level [18].

In this work, the proposed HFS is applied to classify the objectives $\mathrm{OBJ}_{\mathrm{i}}(\mathrm{i}=1 \ldots \mathrm{n})$ of the QMS control problem. Every objective consists of $m$ performance indicators $\mathrm{IP}_{\mathrm{i}, \mathrm{j}}$

$(\mathrm{i}=1 \ldots \mathrm{n}$ and $\mathrm{j}=1 \ldots \mathrm{m})$. Furthermore, every performance indicator is associated with $\mathrm{k}$ measurements $\mathrm{M}_{\mathrm{i}, \mathrm{j}, \alpha}(\mathrm{i}=1, \ldots, \mathrm{n}, \mathrm{j}=1, \ldots, \mathrm{m}$ and $\alpha=1, \ldots, \mathrm{k})\left\{\mathrm{IP}_{\mathrm{i}, \mathrm{j}}=\mathrm{f}\right.$ $\left.\left(\mathrm{M}_{\mathrm{i}, \mathrm{j}, \alpha}\right)\right\}$. Every measurement is included in the fuzzy set of the correspondent performance indicator. It is then interpreted that $\mathrm{i}$ refers to the target number, $\mathrm{j}$ to the indicator number and $\mathrm{k}$ to the measurement number. For example, $\mathbf{M}_{5,1,3}$ is the third measure of the first performance indicator of the fifth objective.

The equations (1), (2) and (3) define the relationship between the indicator upper level and the measurement lower one, the objective upper level and the indicator lower one and the last level, denoted $\mathrm{a}_{\mathrm{i}, \mathrm{j}, \alpha}, \mathrm{a}_{\mathrm{i}, \mathrm{j}}$ and $\mathrm{a}_{\mathrm{i}}, \mathrm{a}_{\mathrm{i}}$.

$a_{i, j ; \alpha}=\frac{\sum_{\alpha=1}^{k} W_{i, j, \alpha} M_{i, j, \alpha}}{\sum_{\alpha=1}^{k} W_{i, j, \alpha}}$

$a_{i, j}=\frac{\sum_{j=1}^{m} W_{i, j} I_{i, j}}{\sum_{j=1}^{m} W_{i, j}}$

$a_{i}=\frac{\sum_{i=1}^{n} W_{i} O B B J_{i}}{\sum_{i=1}^{n} W_{i}}$ 


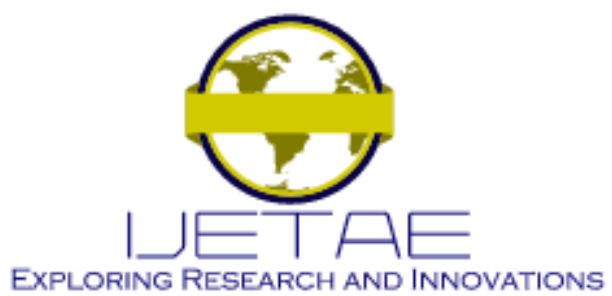

International Journal of Emerging Technology and Advanced Engineering

Website: www.ijetae.com (E-ISSN 2250-2459, Scopus Indexed, ISO 9001:2008 Certified Journal, Volume 11, Issue 11, November 2021)

Where: $\mathrm{W}_{\mathrm{i}, \mathrm{j}, \alpha}$ is the weight associated with the measurement leaf $\mathrm{M}_{\mathrm{i}, \mathrm{j}, \alpha}, \mathrm{W}_{\mathrm{i}, \mathrm{j}}$ is the weight associated with the indicator branch $\mathrm{IP}_{\mathrm{i}, \mathrm{j}}$ and $\mathrm{W}_{\mathrm{i}}$ is the weight associated with the objective branch $\mathrm{OBJ}_{\mathrm{i}}$. In fact, the integration of the weight concept for the QMS control is essential for the measurement standardization that varies proportionally [19]. Figure 2 shows the HFS structure used for QMS control.

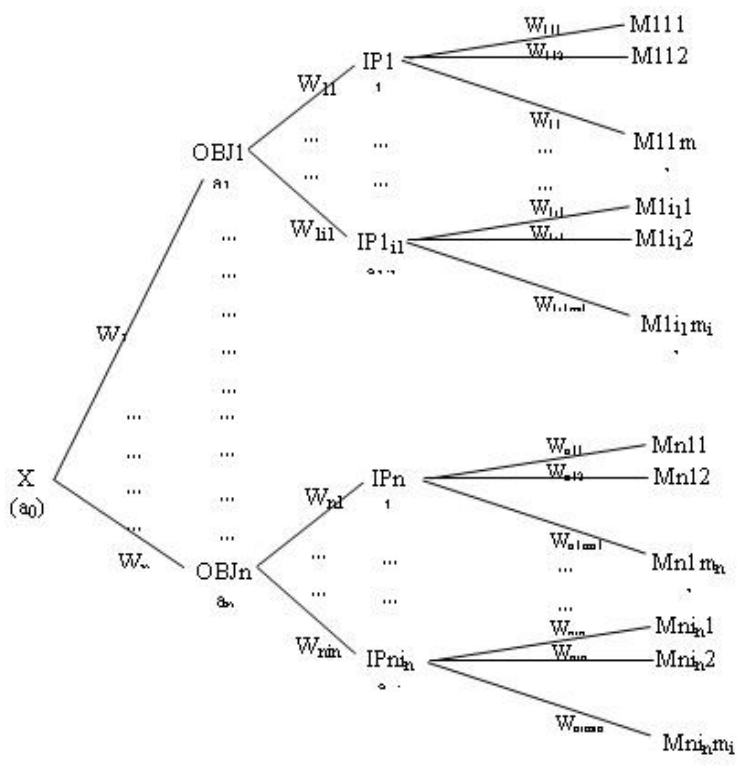

FIGURE 2.HFS FORQMS CONTROL.

\section{B. Hierarchical Neuro-Fuzzy Hybrid System}

Neural Network (NN) and Fuzzy Inference System (FIS) paradigms are frequently applied together. In fact, these two concepts have been combined due to the difficulties and inherent limitations of each isolated paradigm. Therefore, when combined, they are called Neuro-Fuzzy Systems. This system has the advantages of learning through patterns and the easy interpretation of its functionality. The proposed approach NFHH requires structural and parametric identifications [20].

- Structural identification: The QMS control problem includes various performance indicators which are the principal elements of the decision-making process.

These indicators are quantitative and qualitative. This heterogeneous aspect is mostly managed by the application of cooperative structure between the NN and the FIS, namely.
Thus, the NFHH structure is investigated. By the way, the FIS located on the lower level, transforms quantitative indicators $\left(\mathrm{IP}_{11}, \mathrm{IP}_{12} \ldots \mathrm{IP}_{\mathrm{p}, \mathrm{m}, \mathrm{p}}\right)$ into qualitative objectives. Therefore, NFHH manages two types of inputs which are the outputs of qualitative FIS $\left(\mathrm{OBJ}_{1}, \ldots, \mathrm{OBJ}_{\mathrm{p}}\right)$ and the qualitative indicators $\left(\mathrm{IP}_{1}, \mathrm{IP}_{2}, \ldots, \mathrm{IP}_{\mathrm{z}}\right)$.

The NFHH structure is illustrated in Figure 3.

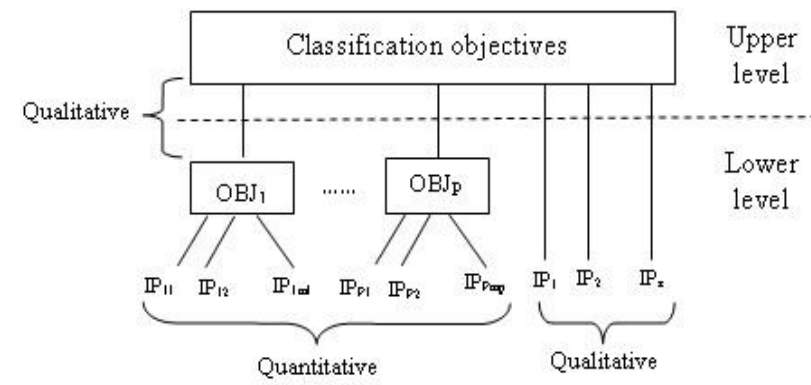

FigURE 3. STRUCTURE OF NFHH

- Parametric identification: In this study, parametric identification deals with the fuzzy membership functions and the neural connective weights. However, it requires an adaptation law. Figure 4 illustrates the block diagram of NFHH structure in the learning phase.

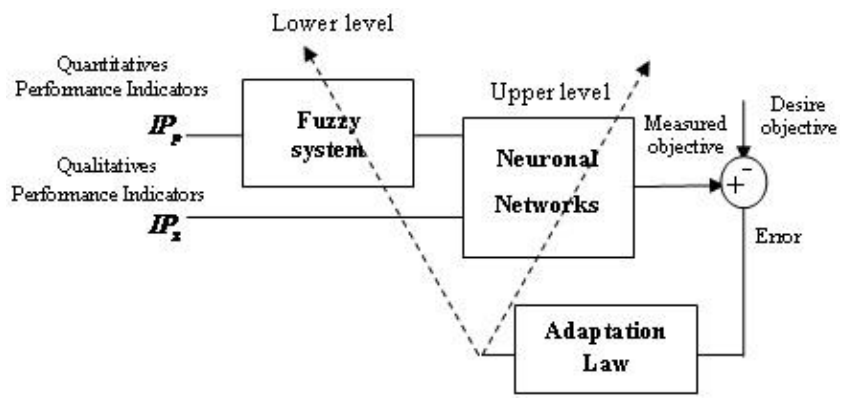

FigURE 4. LEARNING SYSTEM OF NFHH.

Design of the Fuzzy system: The adopted fuzzy structure is identical to that of ANFIS with Mamdani type rules. Indeed, the premises (if) and the consequence (then) of a rule $\mathrm{R}^{\mathrm{i}}$ are fuzzy propositions of the form (4).

$\mathrm{R}^{\mathrm{i}}: \operatorname{IF}\left(\mathrm{x}_{1}\right.$ is $\left.\mu_{1}^{\mathrm{i}}\right)$ AND ........AND $\left(\mathrm{x}_{\mathrm{n}}\right.$ is $\left.\mu_{\mathrm{n}}^{\mathrm{i}}\right) \operatorname{THEN}\left(\mathrm{Y}\right.$ is $\left.\mathrm{B}^{\mathrm{i}}\right)$

Where: $\mathrm{X}=\left[\begin{array}{llll}\mathrm{x}_{1} & \ldots & \mathrm{x}_{\mathrm{j}} \ldots \mathrm{x}_{\mathrm{n}}\end{array}\right]^{\mathrm{T}}$ and $\mathrm{Y}$ are respectively the input and output vectors, $\mu_{p}^{i}$ and $B_{i}$ are respectively the linguistic terms of $\mathrm{X}$ and $\mathrm{Y}$. 


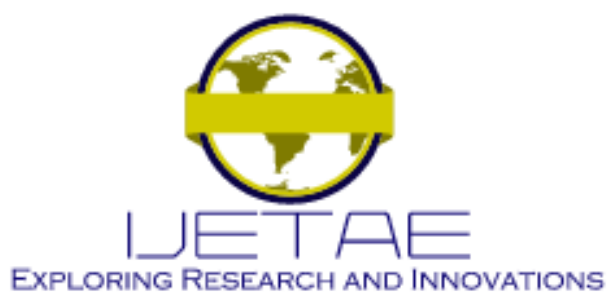

\section{International Journal of Emerging Technology and Advanced Engineering}

Website: www.ijetae.com (E-ISSN 2250-2459, Scopus Indexed, ISO 9001:2008 Certified Journal, Volume 11, Issue 11, November 2021)

In the QMS study, we choose for the $\mathrm{p}^{\text {th }}$ objective, $X_{\mathrm{p}}$ as input vector representing the corresponding performance indicators $\mathrm{IP}_{\mathrm{p}}=\left(\mathrm{IP}_{\mathrm{P} 1}, \mathrm{IP}_{\mathrm{P} 2}, \ldots, \mathrm{IP}_{\mathrm{Pmp}}\right)$ with $\mathrm{m}_{\mathrm{p}}$ input variables $X_{\mathrm{p}}$.

The defuzzification method is chosen to transform the information provided by the fuzzy inference mechanism into numerical value. In this study, the aggregation method is selected. It is represented by the equation (5).

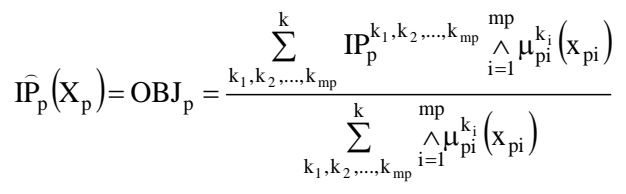

Where: $\mathrm{IP}_{\mathrm{p}}$ is the output of $\mathrm{p}^{\text {th }}$ objective, $\mathrm{IP}_{\mathrm{p}}^{\mathrm{k}_{1}, \mathrm{k}_{2}, \ldots, \mathrm{k}_{\mathrm{mp}}}$

is the consequence of fuzzy rule $\left(\mathrm{k}_{1}, \mathrm{k}_{2}, \ldots, \mathrm{k}_{\mathrm{mp}}\right)^{\text {th }}$ and $\mu_{\mathrm{pi}}^{\mathrm{k}_{\mathrm{i}}}\left(\mathrm{x}_{\mathrm{pi}}\right)$ is the membership degree corresponding to $\left(\mathrm{x}_{\mathrm{pi}}\right)$ for the fuzzy term $\mathrm{k}_{\mathrm{i}}^{\text {th }}$.

The equation (5) can be transformed in the form (6).

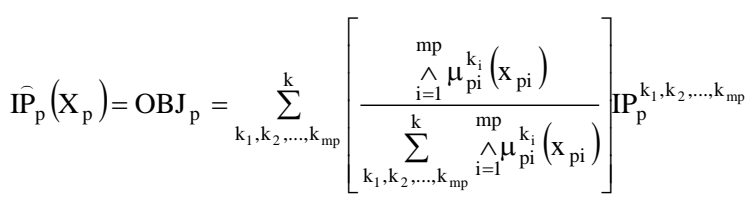

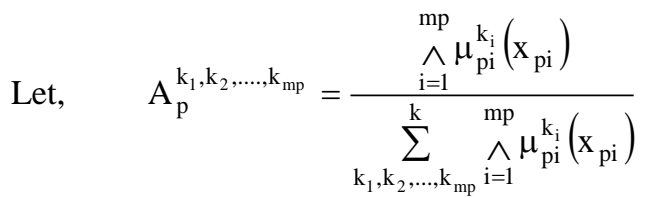

The equation (6) can be written in the form (7).

$$
\operatorname{IP}_{\mathrm{p}}\left(\mathrm{X}_{\mathrm{p}}\right)=\sum_{\mathrm{k}_{1}, \mathrm{k}_{2}, \ldots, \mathrm{k}_{\mathrm{mp}}} \mathrm{A}_{\mathrm{k}}^{\mathrm{k}_{1}, \mathrm{k}_{2}, \ldots, \mathrm{k}_{\mathrm{mp}}}\left(\mathrm{X}_{\mathrm{p}}\right) \cdot \mathrm{IP}_{\mathrm{p}}^{\mathrm{k}_{1}, \mathrm{k}_{2}, \ldots, \mathrm{k}_{\mathrm{mp}}}
$$

Design of Neural Network block: We have chosen the unidirectional type of the NN structure for the QMS control. This structure is represented by an input layer treating the ANFIS outputs $(\mathrm{OBJ} 1, \ldots, \quad \mathrm{OBJp})$ and qualitative indicators (IP1,.., IPz) and an output layer delivering the final decision $y$. One of the advantages of this structure is the capability of automatic learning and simplicity of rules. Figure 5 shows the selected neural structure.

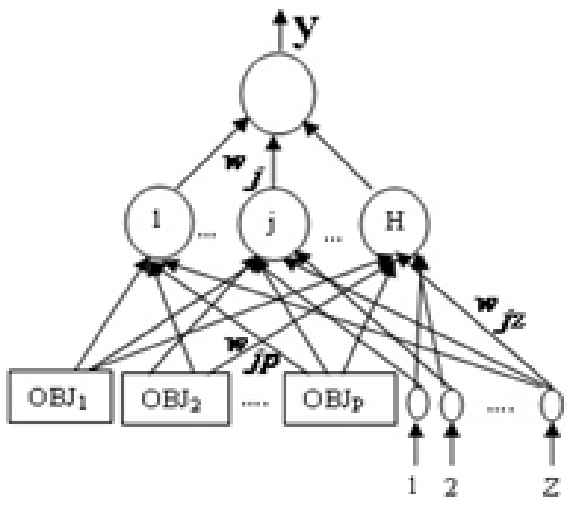

Figure 5. Neural Structure.

This network is a multilayer perceptron type with an output y given by equation (8).

$$
y=f(x)=\sum_{j=1}^{H} w_{j} h_{j}
$$

Where $\mathrm{X}$ is the input vector, $\mathrm{j}$ is the index of hidden neurons and $\mathrm{H}$ is the total number of neurons.

The $h_{j}$ parameter, which represents the $j^{\text {th }}$ output neuron, is given by equation (9).

$$
\mathrm{h}_{\mathrm{i}}=\sigma\left(\sum_{\mathrm{p}=1}^{\mathrm{P}} \mathrm{w}_{\mathrm{jp}} \widehat{\mathrm{IP}}_{\mathrm{p}}+\sum_{\mathrm{z}=1}^{\mathrm{Z}} \mathrm{w}_{\mathrm{jz}} \mathrm{IP}_{\mathrm{z}}\right)
$$

Where $\mathrm{p}=(1,2, \ldots, \mathrm{P})$ is the index of measurement number to the lower level, $\widehat{I P}_{\mathrm{p}}$ is the input of $\mathrm{p}^{\text {th }}$ objective to the upper level, $\mathrm{IP}_{\mathrm{z}}$ is the $\mathrm{z}^{\text {th }}$ qualitative input for the upper level, $w_{j}$ is the connection weights and $\sigma$ is the activation function chosen sigmoid. 


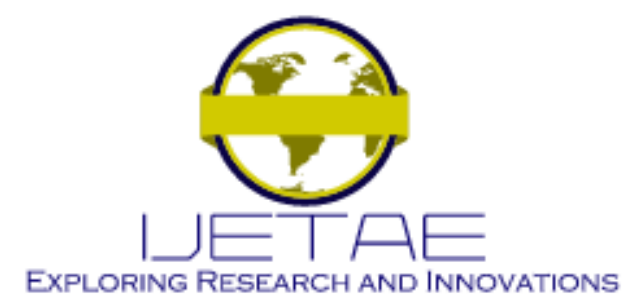

International Journal of Emerging Technology and Advanced Engineering

Website: www.ijetae.com (E-ISSN 2250-2459, Scopus Indexed, ISO 9001:2008 Certified Journal, Volume 11, Issue 11, November 2021)

If we replace $h_{j}$ and $\widehat{I P}_{\mathrm{p}}$ by their expressions (9) and (7) into (8), the output y is represented by equation (10).

$$
\mathrm{y}=\sum_{\mathrm{j}=1}^{\mathrm{H}}\left[\mathrm{w}_{\mathrm{i}} \sigma\left(\sum_{\mathrm{p}=1}^{\mathrm{P}} \mathrm{w}_{\mathrm{jp}} \hat{\mathrm{IP}}_{\mathrm{p}}+\sum_{\mathrm{z}=1}^{\mathrm{Z}} \mathrm{w}_{\mathrm{jz}} \mathrm{IP}_{\mathrm{z}}\right)\right]
$$

Learning based on the gradient algorithm: The goal of the learning phase is to modify, by adapting the network parameters (weight), the behaviour of the network until a desired one. For this adaptation, the learning algorithm used is the back propagation method using the gradient descent.

For the QMS control, the adaptation takes into account the membership functions noted $A_{p}$ for the fuzzy system, and the connection weights noted $\left(\mathrm{w}_{\mathrm{j}}, \mathrm{w}_{\mathrm{jp}}\right.$ and $\left.\mathrm{w}_{\mathrm{j} z}\right)$ for the neural system. The principle of this algorithm is to minimize the sum $\mathrm{E}$ of squared errors given by expression (11) during a predefined time horizon. The quadratic form is required to deliver positive quantities.

$$
\min _{\mathrm{w}_{\mathrm{j}}, \mathrm{w}_{\mathrm{jp}}, \mathrm{w}_{\mathrm{jz}}, \mathrm{A}_{\mathrm{p}}} \mathrm{E}=\sum_{\mathrm{k}} \mathrm{E}_{\mathrm{k}}
$$

Where $E_{k}$ is the square error which is a function of the error $e_{k}$ between the desired output $y_{k}^{d}$ and the neuron output $\mathrm{y}_{\mathrm{k}}$ is given by equation (12).

$$
\mathrm{E}_{\mathrm{k}}=\frac{1}{2}\left(\mathrm{y}_{\mathrm{k}}-\mathrm{y}_{\mathrm{k}}^{\mathrm{d}}\right)^{2}=\frac{1}{2} \mathrm{e}_{\mathrm{k}}^{2}
$$

However, minimizing $\mathrm{E}$ is equivalent to minimizing $\mathrm{E}_{\mathrm{k}}$ because it represents a positive quantity which should converge to 0 . To this end, calculating the derivative $\frac{\partial \mathrm{E}_{\mathrm{k}}}{\partial \mathrm{x}}$ of $E_{k}$ relative to $x$ with $x \in\left\{w_{j}, w_{j p}, w_{j z}, A_{p}\right\}$ is sufficient. For a step gradient $\eta_{1}$, the adaptation of $\mathrm{x}$ is given by equation (13).

$$
\mathrm{x}(\mathrm{k}+1)=\mathrm{x}(\mathrm{k})-\eta_{1} \frac{\partial \mathrm{E}_{\mathrm{k}}}{\partial \mathrm{x}}
$$

\section{- Learning for the neural network block}

For the network output, calculating $\min _{w_{j}} E_{k}$ is given $\frac{\partial \mathrm{E}_{\mathrm{k}}}{\partial \mathrm{w}_{\mathrm{j}}}$ in form (14).

$$
\frac{\partial \mathrm{E}_{\mathrm{k}}}{\partial \mathrm{w}_{\mathrm{j}}}=\frac{\partial \mathrm{E}_{\mathrm{k}}}{\partial \mathrm{y}_{\mathrm{k}}} * \frac{\partial \mathrm{y}_{\mathrm{k}}}{\partial \mathrm{w}_{\mathrm{j}}}=\frac{\partial \mathrm{E}_{\mathrm{k}}}{\partial \mathrm{e}_{\mathrm{k}}} * \frac{\partial \mathrm{e}_{\mathrm{k}}}{\partial \mathrm{y}_{\mathrm{k}}} * \frac{\partial \mathrm{y}_{\mathrm{k}}}{\partial \mathrm{w}_{\mathrm{j}}}
$$

However, $\frac{\partial \mathrm{E}_{\mathrm{k}}}{\partial \mathrm{e}_{\mathrm{k}}}=\mathrm{e}_{\mathrm{k}}$ and $\frac{\partial \mathrm{y}_{\mathrm{k}}}{\partial \mathrm{w}_{\mathrm{j}}}=\mathrm{h}_{\mathrm{j}}$ (seen in equation (9)), given by:

$$
\frac{\partial \mathrm{E}_{\mathrm{k}}}{\partial \mathrm{w}_{\mathrm{j}}}=\mathrm{e}_{\mathrm{k}} * \mathrm{~h}_{\mathrm{j}}
$$

Therefore, the adaptation of parameter $\mathrm{w}_{\mathrm{j}}$ is presented by equation (16).

$$
\begin{aligned}
& \mathrm{w}_{\mathrm{j}}(\mathrm{k}+1)=\mathrm{w}_{\mathrm{j}}(\mathrm{k})-\eta_{1} * \frac{\partial \mathrm{E}_{\mathrm{k}}}{\partial \mathrm{w}_{\mathrm{j}}} \\
& \mathrm{w}_{\mathrm{j}}(\mathrm{k}+1)=\mathrm{w}_{\mathrm{j}}(\mathrm{k})-\eta_{1} * \mathrm{e}_{\mathrm{k}} * \mathrm{~h}_{\mathrm{j}}
\end{aligned}
$$

For the output of the hidden layer, we obtain equations 17 and 18.

$$
\begin{aligned}
& \frac{\partial \mathrm{E}_{\mathrm{k}}}{\partial \mathrm{w}_{\mathrm{jp}}}=\frac{\partial \mathrm{E}_{\mathrm{k}}}{\partial \mathrm{y}_{\mathrm{k}}} * \frac{\partial \mathrm{y}_{\mathrm{k}}}{\partial \mathrm{w}_{\mathrm{jp}}}=\mathrm{e}_{\mathrm{k}} * \frac{\partial \mathrm{y}_{\mathrm{k}}}{\partial \mathrm{w}_{\mathrm{jp}}} \\
& \text { with : } \frac{\partial \mathrm{y}_{\mathrm{k}}}{\partial \mathrm{w}_{\mathrm{jp}}}=\frac{\partial \mathrm{y}_{\mathrm{k}}}{\partial \mathrm{h}_{\mathrm{j}}} * \frac{\partial \mathrm{h}_{\mathrm{j}}}{\partial \mathrm{w}_{\mathrm{jp}}}=\mathrm{w}_{\mathrm{j}} * \mathrm{~h}_{\mathrm{j}} *\left(1-\mathrm{h}_{\mathrm{j}}\right) * \mathrm{IP}_{\mathrm{p}} \\
& \frac{\partial \mathrm{E}_{\mathrm{k}}}{\partial \mathrm{w}_{\mathrm{jz}}}=\frac{\partial \mathrm{E}_{\mathrm{k}}}{\partial \mathrm{y}_{\mathrm{k}}} * \frac{\partial \mathrm{y}_{\mathrm{k}}}{\partial \mathrm{w}_{\mathrm{jz}}}=\mathrm{e}_{\mathrm{k}} * \frac{\partial \mathrm{y}_{\mathrm{k}}}{\partial \mathrm{w}_{\mathrm{jz}}} \\
& \text { with: } \frac{\partial \mathrm{y}_{\mathrm{k}}}{\partial \mathrm{w}_{\mathrm{jz}}}=\frac{\partial \mathrm{y}_{\mathrm{k}}}{\partial \mathrm{h}_{\mathrm{j}}} * \frac{\partial \mathrm{h}_{\mathrm{j}}}{\partial \mathrm{w}_{\mathrm{jz}}}=\mathrm{w}_{\mathrm{j}} * \mathrm{~h}_{\mathrm{j}} *\left(1-\mathrm{h}_{\mathrm{j}}\right) * \mathrm{IP}_{\mathrm{z}}
\end{aligned}
$$

What gives the equations 19 and 20.

$$
\begin{aligned}
& \frac{\partial \mathrm{E}_{\mathrm{k}}}{\partial \mathrm{w}_{\mathrm{jp}}}=\mathrm{w}_{\mathrm{j}} * \mathrm{~h}_{\mathrm{j}} *\left(1-\mathrm{h}_{\mathrm{j}}\right) * \mathrm{IP}_{\mathrm{p}} \\
& \frac{\partial \mathrm{E}_{\mathrm{k}}}{\partial \mathrm{w}_{\mathrm{jz}}}=\mathrm{w}_{\mathrm{j}} * \mathrm{~h}_{\mathrm{j}} *\left(1-\mathrm{h}_{\mathrm{j}}\right) * \mathrm{IP}_{\mathrm{z}}
\end{aligned}
$$

The adaptation of the two parameters $\mathrm{w}_{\mathrm{jp}}$ and $\mathrm{w}_{\mathrm{jz}}$ are given by equations (21) and (22).

$$
\begin{aligned}
& \mathrm{w}_{\mathrm{jp}}(\mathrm{k}+1)=\mathrm{w}_{\mathrm{jp}}(\mathrm{k})-\eta_{1} * \frac{\partial \mathrm{E}_{\mathrm{k}}}{\partial \mathrm{w}_{\mathrm{jp}}} \\
& \mathrm{w}_{\mathrm{jp}}(\mathrm{k}+1)=\mathrm{w}_{\mathrm{jp}}(\mathrm{k})-\eta_{1} * \mathrm{e}_{\mathrm{k}} * \mathrm{w}_{\mathrm{j}} \mathrm{h}_{\mathrm{j}} *\left(1-\mathrm{h}_{\mathrm{j}}\right)-\mathrm{IP}_{\mathrm{p}}
\end{aligned}
$$




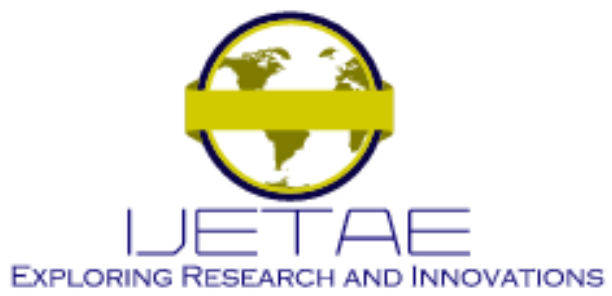

International Journal of Emerging Technology and Advanced Engineering

Website: www.ijetae.com (E-ISSN 2250-2459, Scopus Indexed, ISO 9001:2008 Certified Journal, Volume 11, Issue 11, November 2021)

$$
\begin{aligned}
& \mathrm{w}_{\mathrm{jz}}(\mathrm{k}+1)=\mathrm{w}_{\mathrm{jz}}(\mathrm{k})-\eta_{1} * \frac{\partial \mathrm{E}_{\mathrm{k}}}{\partial \mathrm{w}_{\mathrm{jz}}} \\
& \mathrm{w}_{\mathrm{jz}}(\mathrm{k}+1)=\mathrm{w}_{\mathrm{jz}}(\mathrm{k})-\eta_{1} * \mathrm{e}_{\mathrm{k}} * \mathrm{w}_{\mathrm{j}} \mathrm{h}_{\mathrm{j}} *\left(1-\mathrm{h}_{\mathrm{j}}\right)-\mathrm{IP}_{\mathrm{z}}
\end{aligned}
$$

- Learning for the fuzzy system

For learning fuzzy system, the adaptation takes into account the membership functions $A_{p}^{k_{1}, k_{2}, \ldots ., k_{m p}}$. To do so, we must calculate the derivative of $E_{k}$ relative to $\mathrm{A}_{\mathrm{p}}^{\mathrm{k}_{1}, \mathrm{k}_{2}, \ldots, \mathrm{k}_{\mathrm{mp}}}$.

$\frac{\partial \mathrm{E}_{\mathrm{k}}}{\partial \mathrm{A}_{\mathrm{p}}^{\mathrm{k}_{1}, \mathrm{k}_{2}, \ldots, \mathrm{k}_{\mathrm{mp}}}}=\frac{\partial \mathrm{E}_{\mathrm{k}}}{\partial \widehat{\mathrm{IP}}_{\mathrm{p}}} * \frac{\partial \widehat{\mathrm{I}}_{\mathrm{p}}}{\partial \mathrm{A}_{\mathrm{p}}^{\mathrm{k}_{1}, \mathrm{k}_{2}, \ldots, \mathrm{k}_{\mathrm{mp}}}}=\frac{\partial \mathrm{E}_{\mathrm{k}}}{\partial \mathrm{y}_{\mathrm{k}}} * \frac{\partial \mathrm{y}_{\mathrm{k}}}{\partial \widehat{\mathrm{IP}}_{\mathrm{p}}}$

$\frac{\partial \mathrm{E}_{\mathrm{k}}}{\partial \mathrm{A}_{\mathrm{p}}^{\mathrm{k}_{1}, \mathrm{k}_{2}, \ldots, \mathrm{k}_{\mathrm{mp}}}}=\mathrm{e}_{\mathrm{k}} * \frac{\partial \mathrm{y}_{\mathrm{k}}}{\partial \widehat{I P}_{\mathrm{p}}} * \frac{\partial \mathrm{IP}_{\mathrm{p}}}{\partial \mathrm{A}_{\mathrm{p}}^{\mathrm{k}_{1}, \mathrm{k}_{2}, \ldots, \mathrm{k}_{\mathrm{mp}}}}$

Where:

$\frac{\partial \mathrm{y}_{\mathrm{k}}}{\partial \widehat{\mathrm{IP}}_{\mathrm{p}}}=\sum_{\mathrm{j}=1}^{\mathrm{H}} \frac{\partial \mathrm{y}_{\mathrm{k}}}{\partial \mathrm{h}_{\mathrm{j}}} * \frac{\partial \mathrm{h}_{\mathrm{j}}}{\partial \widehat{\mathrm{IP}}_{\mathrm{p}}}=\sum_{\mathrm{j}=1}^{\mathrm{H}} \mathrm{w}_{\mathrm{j}} * \mathrm{~h}_{\mathrm{j}} *\left(1-\mathrm{h}_{\mathrm{j}}\right) * \mathrm{w}_{\mathrm{jp}}$

And $\frac{\partial \widehat{I P}_{\mathrm{p}}}{\partial \mathrm{A}_{\mathrm{p}}^{\mathrm{k}_{1}, \mathrm{k}_{2}, \ldots, \mathrm{k}_{\mathrm{mp}}}}=\mathrm{IP}_{\mathrm{p}}^{\mathrm{k}_{1}, \mathrm{k}_{2}, \ldots, \mathrm{k}_{\mathrm{mp}}}$

Replacing the two expressions of equation (24) in equation (23), we obtain the equation (25).

$$
\frac{\partial \mathrm{E}_{\mathrm{k}}}{\partial \mathrm{A}_{\mathrm{p}}^{\mathrm{k}_{1}, \mathrm{k}_{2}, \ldots, \mathrm{k}_{\mathrm{mp}}}}=\mathrm{e}_{\mathrm{k}} \sum_{\mathrm{j}=1}^{\mathrm{H}} \mathrm{w}_{\mathrm{j}} * \mathrm{~h}_{\mathrm{j}} *\left(1-\mathrm{h}_{\mathrm{j}}\right) * \mathrm{w}_{\mathrm{jp}} * \mathrm{IP}_{\mathrm{p}}^{\mathrm{k}}
$$

The adaptation of parameter $\mathrm{A}_{\mathrm{p}}^{\mathrm{k}_{1}, \mathrm{k}_{2}, \ldots ., \mathrm{k}_{\mathrm{mp}}}$ is given by equation (26).

$$
\begin{aligned}
& \mathrm{A}_{\mathrm{p}}^{\mathrm{k}_{1}, \mathrm{k}_{2}, \ldots, \mathrm{k}_{\mathrm{mp}}}(\mathrm{k}+1)=\mathrm{A}_{\mathrm{p}}^{\mathrm{k}_{1}, \mathrm{k}_{2}, \ldots, \mathrm{k}_{\mathrm{mp}}}(\mathrm{k})-\eta_{1} * \frac{\partial \mathrm{E}_{\mathrm{k}}}{\partial \mathrm{A}_{\mathrm{p}}^{\mathrm{k}_{1}, \mathrm{k}_{2}, \ldots, \mathrm{k}_{\mathrm{mp}}}} \\
& \mathrm{A}_{\mathrm{p}}^{\mathrm{k}_{1}, \mathrm{k}_{2}, \ldots, \mathrm{k}_{\mathrm{mp}}}(\mathrm{k}+1)=\mathrm{A}_{\mathrm{p}}^{\mathrm{k}_{1}, \mathrm{k}_{2}, \ldots, \mathrm{k}_{\mathrm{mp}}(\mathrm{k})-} \\
& \eta_{1} * \mathrm{e}_{\mathrm{k}} * \sum_{1}^{\mathrm{H}} \mathrm{w}_{\mathrm{j}} * \mathrm{~h}_{\mathrm{j}} *\left(1-\mathrm{h}_{\mathrm{j}}\right) * \mathrm{w}_{\mathrm{jp}} * \mathrm{IP}_{\mathrm{p}}^{\mathrm{k}_{1}, \mathrm{k}_{2}, \ldots, \mathrm{k}_{\mathrm{mp}}}
\end{aligned}
$$

\section{- Learning algorithm}

The learning gradient algorithm developed for the overall structure NFHH consists of several steps which are defined in Figure 6.

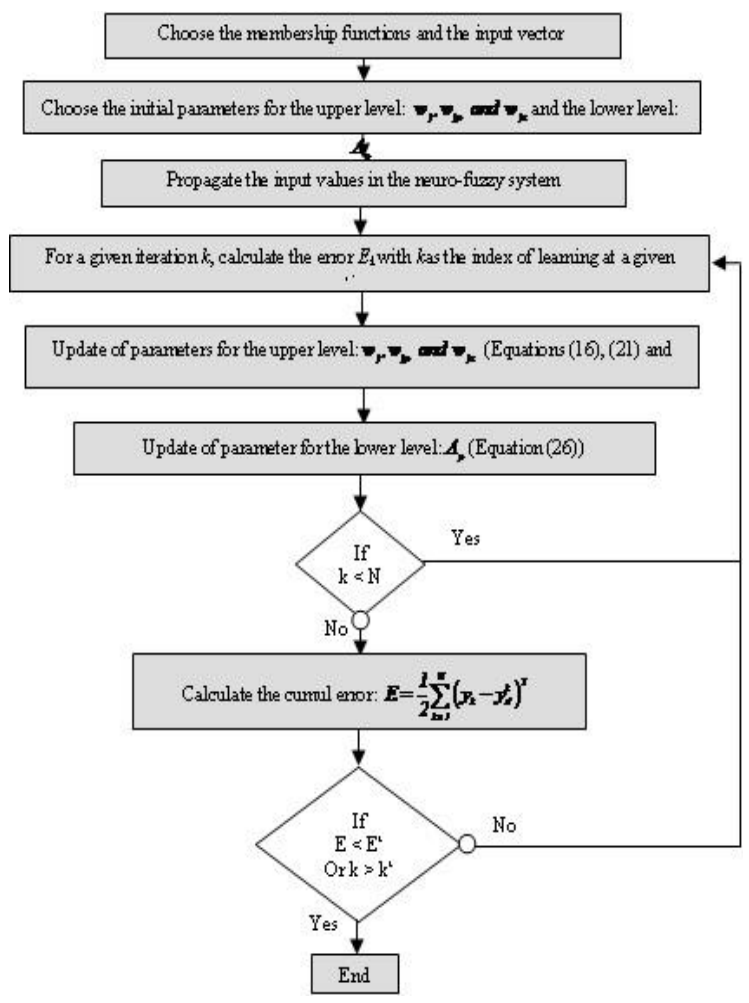

Figure 6. NeUral Structure Learning Algorithm.

Firstly, the learning parameters $\left(\mathrm{A}_{\mathrm{p}}, \mathrm{w}_{\mathrm{j}}, \mathrm{w}_{\mathrm{jp}}\right.$ and $\left.\mathrm{w}_{\mathrm{jz}}\right)$ are initialized. Then, they are propagated in the Neuro-Fuzzy network in order to calculate the error $E_{k}$ for a given iteration $\mathrm{k}$. Then, it is necessary to update the parameters and calculate the accumulated error $E=\frac{1}{2} \sum_{k=1}^{n}\left(y_{k}-y_{k}^{d}\right)^{2}$, in case $\mathrm{k}$ is less than the size of the training set. If the conditions ( $\mathrm{E}$ less than the tolerated error $\mathrm{E}^{\mathrm{t}}$ or $\mathrm{k}$ superior than the number of iterations tolerated $\mathrm{k}^{\mathrm{t}}$ ) are true then end of the algorithm. Else, we go back to the previous step (calculating for a given iteration $\mathrm{k}$ the error $\mathrm{E}_{\mathrm{k}}$ ). 


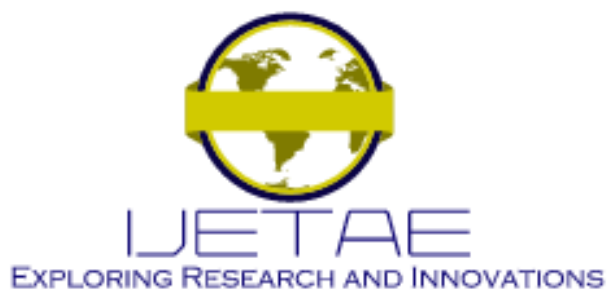

International Journal of Emerging Technology and Advanced Engineering

Website: www.ijetae.com (E-ISSN 2250-2459, Scopus Indexed, ISO 9001:2008 Certified Journal, Volume 11, Issue 11, November 2021)

\section{CASE Study: Industrial COMPANy}

The case of an industrial company, operating in the electromechanical sector, is invested in this paper. This company incorporates a fleet of plastic injection, molding machines and component assembly workshops. A quality production level is requested in order to reach its customers requirements. Thus, the challenge for this company is how to manage its objectives and consequently improve its production. Therefore, the company has to update regularly its objectives by taking into consideration different indicators. Figure 7 cites the company main objectives.

Table I shows the different indicators and objectives per process.

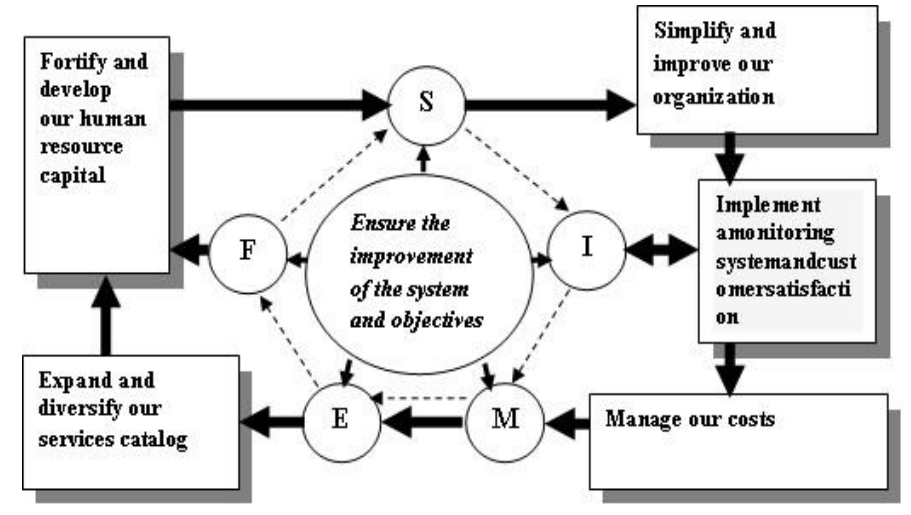

Figure 7. COMPANy OBJECTIVES. 


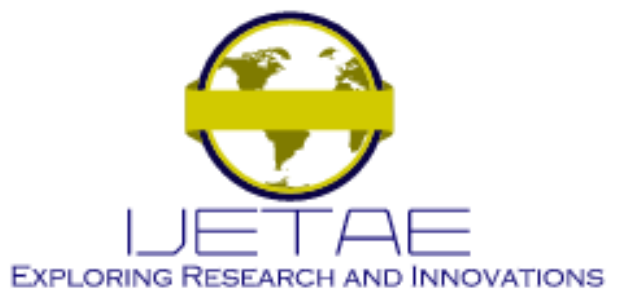

\section{International Journal of Emerging Technology and Advanced Engineering} Website: www.ijetae.com (E-ISSN 2250-2459, Scopus Indexed, ISO 9001:2008 Certified Journal, Volume 11, Issue 11, November 2021)

TABLE I

\section{OBJECTIVES AND PERFORMANCE INDICATORS PER PROCESS.}

\begin{tabular}{|c|c|c|}
\hline Objective & Process & Performance indicators \\
\hline \multirow{20}{*}{$\begin{array}{l}\text { Simplify and } \\
\text { improve our } \\
\text { organization } \\
\text { (S) }\end{array}$} & Procurement and inventory management processes & Compliance rate of clearance time \\
\hline & \multirow{2}{*}{ Color and cabling process } & Internal rate of non-compliance workshop coloring \\
\hline & & Rate of return (workshop wiring) \\
\hline & \multirow{2}{*}{ Cutting process } & Internal noncompliance rate of cutting \\
\hline & & Synthetic rate of return (workshop cut) \\
\hline & \multirow{6}{*}{ Injection and assembly process } & Internal rate of non-compliance workshop injection \\
\hline & & Rate of noncompliance internal molding workshop \\
\hline & & Synthetic rate of return (workshop injection) \\
\hline & & Synthetic rate of return (molding workshop) \\
\hline & & Internal rate of non-compliance workshop accessory \\
\hline & & Rate of return (workshop accessory) \\
\hline & \multirow{9}{*}{ Maintenance process } & Availability rate of molding presses \\
\hline & & Synthetic rate of return \\
\hline & & Discontinuation rate workshop accessories \\
\hline & & Discontinuation rates wiring workshop \\
\hline & & Rate cut-off workshop \\
\hline & & Discontinuation rate electronic workshop \\
\hline & & Discontinuation rate of injection molding machines \\
\hline & & Discontinuation rates molding presses \\
\hline & & Discontinuation rate of injection devices \\
\hline \multirow{8}{*}{$\begin{array}{l}\text { Implement a } \\
\text { monitoring system } \\
\text { and customer } \\
\text { satisfaction } \\
\text { (I) }\end{array}$} & \multirow{2}{*}{ Customer process } & Rate of customer complaints \\
\hline & & Rate of customer satisfaction \\
\hline & \multirow{2}{*}{ Color and cabling process } & Non-compliance rate detected by the customer coloration \\
\hline & & Non-compliance rate detected by the customer wiring workshop \\
\hline & Cutting process & Non-compliance rate detected by the customer cutting workshop \\
\hline & \multirow{3}{*}{ Injection and assembly process } & Non-compliance rate detected by the customer workshop injection \\
\hline & & Non-compliance rate detected by the customer molding workshop \\
\hline & & Non-compliance rate detected by the customer accessories \\
\hline \multirow{4}{*}{$\begin{array}{l}\text { Manage our costs } \\
\text { (M) }\end{array}$} & Customer process & Rate of customer complaints \\
\hline & Process management and continuous improvement objectives & Rate of overall non-compliance \\
\hline & Human resource management process & Rate of absenteeism \\
\hline & Injection process & Rate of non-compliance injection \\
\hline \multirow{2}{*}{$\begin{array}{l}\text { Expand and } \\
\text { diversify our } \\
\text { services catalog }(\mathrm{E})\end{array}$} & \multirow{2}{*}{ Industrialization process } & Average rate of industrialization of a product \\
\hline & & Rate of industrialization of new products \\
\hline \multirow{15}{*}{$\begin{array}{l}\text { Fortify and develop } \\
\text { our human resource } \\
\text { capital } \\
\text { (F) }\end{array}$} & \multirow{15}{*}{ Human resource management process } & Competence rate of injection \\
\hline & & Competence rate of maintenance \\
\hline & & Competence rate of quality \\
\hline & & Competence rate of wiring \\
\hline & & Competence rate of cuttings \\
\hline & & Overall competence rate \\
\hline & & Competence rate of mounting accessories \\
\hline & & Success rate of training \\
\hline & & Polyvalence rate of wiring \\
\hline & & Polyvalence rate of cutting \\
\hline & & Overall polyvalence rate \\
\hline & & Polyvalence rate of injection \\
\hline & & Polyvalence rate of maintenance \\
\hline & & Polyvalence rate of mounting accessories \\
\hline & & Polyvalence rate of quality \\
\hline
\end{tabular}




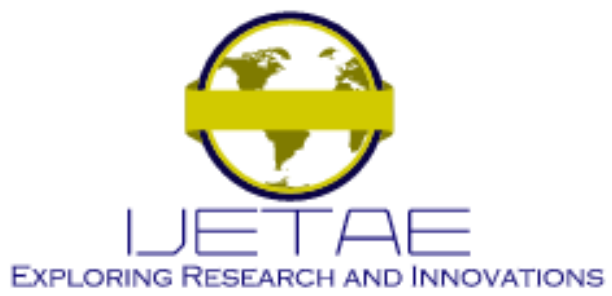

International Journal of Emerging Technology and Advanced Engineering Website: www.ijetae.com (E-ISSN 2250-2459, Scopus Indexed, ISO 9001:2008 Certified Journal, Volume 11, Issue 11, November 2021)

\section{A. Use HFS}

The configuration of the HFS demands the identification of the objectives (level1), performance indicators (level 2) and indicators measures (level 3 .

In this case study, five objectives OBJ1-OBJ5 are identified. For every objective a set of indicators IP11IP515 is associated. For instance, the upper level of variable OBJ3 ("Manage our costs") handles four performance indicators. These indicators form a sub-group (IP31 "rate of customer complaints", IP32 "Rate of overall non-compliance", IP33 "rate of absenteeism" and IP34 "rate of non-compliance injection"). For each performance indicator corresponds five measures. For example, $\mathbf{M}_{3,1,1}$, $\mathrm{M}_{3,1,2}, \mathrm{M}_{3,1,3}, \mathrm{M}_{3,1,4}$ and $\mathrm{M}_{3,1,5}$ belong to IP31 fuzzy set.

The measure vectors associated to performance indicators IP31, IP32, IP33 and IP34 with weights equal to one are presented as follows:

$$
\begin{aligned}
\text { IP3 } 1 & =[0.14,0.23,0.45,0.73,0.90] \\
\text { IP32 } & =[0.08,0.25,0.46,0.74,0.91] \\
\text { IP33 } & =[0.09,0.25,0.46,0.74,0.90] \\
\text { IP34 } & =[0.08,0.26,0.46,0.75,0.90]
\end{aligned}
$$

The upper level (IP31) and the lower one (M311, M312, M313, M314 and M315) are grouped together with an aggregation function a31. This function is identical for the other indicators $(\mathrm{a} 11=\ldots=\mathrm{a} 120=\mathrm{a} 21 \ldots=\mathrm{a} 28=\mathrm{a} 31 \ldots=$ $\mathrm{a} 34=\mathrm{a} 41 \ldots=\mathrm{a} 415)$.

Weighting the performance indicator is a new concept adopted by the company. Therefore, by applying this concept, the company standardizes its production practices across the year. Indeed, the company, under its production strategy, selects the associated weights with each correspondent branch (objective-indicator). For example, the corresponding branch weights (OBJ3-IP3i) are fixed: $\mathrm{w} 31=0.4, \mathrm{w} 32=0.3, \mathrm{w} 33=0.1$ and $\mathrm{w} 34=0.2$. In this case, OBJ3 is calculated using the expression for ai, and is equal to:

$$
\text { OBJ3 }=[0.196,0.146,0.048,0.098]
$$

However, minimizing the rate of customer complaints such as: absenteeism, non-compliance and overall injection (see Table I), is necessary to ensure a good cost control.
The following expression defines the use of the aggregation functions $\mathrm{a}_{3}=\mathrm{Min}$, between the upper $(\mathrm{OBJ} 3)$ and lower (IP31, 32, 33 and 34) levels.

$$
\text { OBJ3 }=\left\{\begin{array}{l}
\text { Min IP31 } \\
\text { Min IP32 } \\
\text { Min IP33 } \\
\text { Min IP34 }
\end{array}\right.
$$

Consequently, the obtained results by applying the minimum aggregation operator are as follows: Min $(0.196$, $0.146,0.048,0.098)=0.048$.

The final HFS structure links the upper level (X) and the lower level (OBJ1, OBJ2, OBJ3, OBJ4 and OBJ5) by involving aggregation functions $\mathrm{a} 0=(\mathrm{a} 1, \mathrm{a} 2, \mathrm{a} 3, \mathrm{a} 4$ and $\mathrm{a} 5)$.

As a result, by referring to the expression below, it is deduced that OBJ4 has to be done firstly, followed by OBJ5, OBJ2, OBJ3 and OBJ1, respectively.

$$
\mathrm{X}=[0.022,0.051,0.048,0.075,0.057]
$$

\section{B. Use NFHH}

The design and development of NFHH approach require structured steps to guarantee a judicious choice of the different parameters involved in the system.

Configuration NFHH: In our case study, we have selected the triangular membership functions because it is the most suitable for this type of problem. This choice is not arbitrary but it is the fruit of several tests of various types and number of membership functions. Therefore, a fuzzy set \{ Very Sensitive (VS), Sensitive (S), Medium (M), High (H) and Very High (VH) $\}$, characterized by a membership function, is associated with every measure (variable). The fuzzy sets for classification objectives are also expressed linguistically ("too little", "slightly little", "little", "high" and "too high") are distinguished by a membership function and. These linguistic terms belong to the set T $=\{\mathrm{VS}, \mathrm{S}, \mathrm{M}$, $\mathrm{H}$ and $\mathrm{VH}\}$ and they are defined on the universe of discourse $[0,1]$

Figure 8 shows the performance indicators membership functions. 


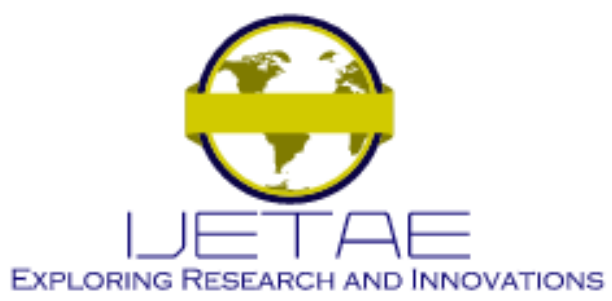

International Journal of Emerging Technology and Advanced Engineering

Website: www.jjetae.com (E-ISSN 2250-2459, Scopus Indexed, ISO 9001:2008 Certified Journal, Volume 11, Issue 11, November 2021)

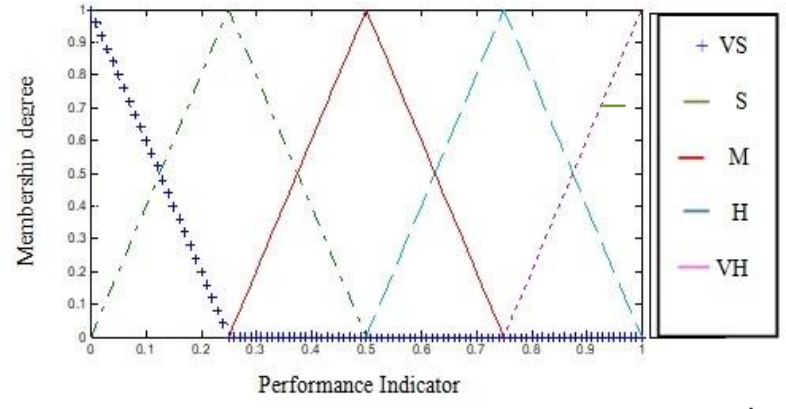

FIGURE 8. MEMBERSHIP FUNCTION OF PERFORMANCE INDICATORS.

In addition, a rule base that consists of collection rules of the form (4) has been established based on expert judgment and history.

To identify the main objective rate, it is recommended to take into consideration the performance indicators measurements and the desired output, by referring to history or experts knowledge. The collected measurements are treated by the inference system. In this case study, the number of rules is eighty one (81). After that, the second layer neurons use T-norm MIN to calculate the accuracy of the antecedent's fuzzy rules. Nevertheless, output objectives are defuzzied by T-conorm MAX and the weighted sum system, as it is represented by the equation (27).

$$
\operatorname{OBBJ}_{\mathrm{p}}\left(\mathrm{x}_{\mathrm{p}}\right)=\frac{\sum_{\mathrm{k}_{1}, \mathrm{k}_{2}, \ldots, \mathrm{k}_{\mathrm{mp}}} \mathrm{OBJ}_{\mathrm{p}}^{\mathrm{k}_{1}, \mathrm{k}_{2}, \ldots, \mathrm{k}_{\mathrm{mp}}} \mu_{\mathrm{p}, \mathrm{i}}^{\mathrm{k}_{\mathrm{i}}}\left(\mathrm{x}_{\mathrm{p}, \mathrm{i}}\right)}{\sum_{\mathrm{k}_{1}, \mathrm{k}_{2}, \ldots, \mathrm{k}_{\mathrm{mp}}}^{\mathrm{k}_{\mathrm{i}}\left(\mathrm{x}_{\mathrm{p}, \mathrm{i}}\right)}}
$$

It is then required to reduce the obtained error in order to ensure the convergence of the approach. Indeed, when the error is under a defined threshold, a learning algorithm will identify the FIS membership functions. The obtained system will be used as an input for the neural system whose its weights have to be calculated by referring to the corresponding objective indicators.

Simulation Results: Simulation data are used to prove the $\mathrm{NFHH}$ advantages over the other approaches regarding the approximation accuracy. Due to the large number of inputs (objective and performance indicator), we present in Table II, the learning models developed for the objective 3 "Manage our costs," which depend on 4 performance indicators (see Table II) denoted by IP31, IP32, IP33 and IP34.
The obtained membership functions of performance indicators (IP31, IP32, IP33 and IP34), after applying the learning algorithm, are presented in Figure 9.

Based on these results, the changes have affected mostly the parameters of the membership functions and particularly the overall non-compliance rate IP32. This indicates the overall level of quality linked to the fixed objective and it is explained by the high non-compliance previous rate and the large number of proposed actions to implement.
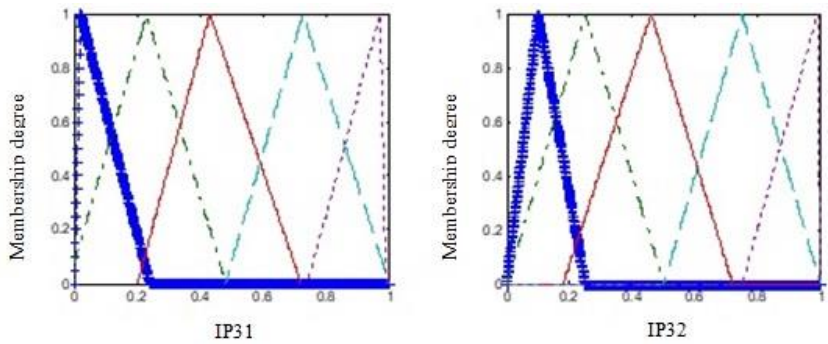

IP32
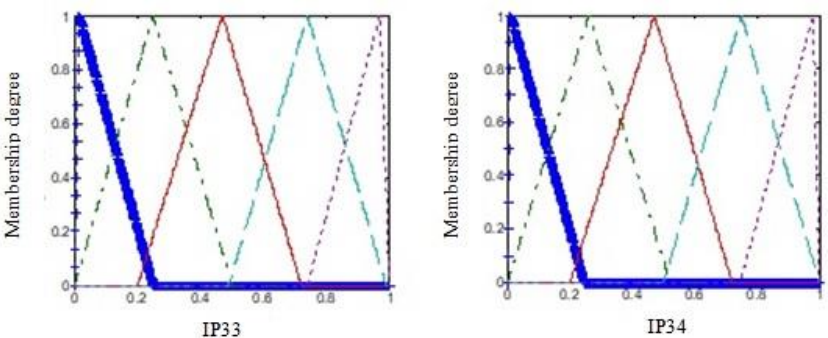

FIGURE9. MEMBERSHIP FUNCTIONS AFTER LEARNING OF PERFORMANCE INDICATORS

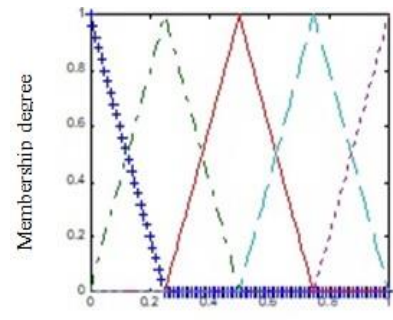

OBJ3-Before

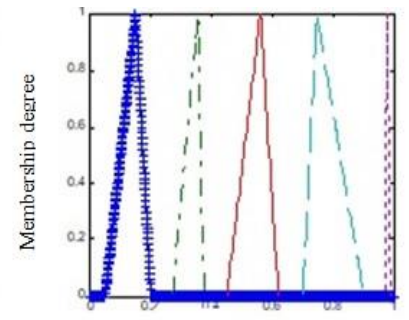

OBJ3-After
FIGURE 10. MEMBERSHIP FUNCTIONS BEFORE AND AFTER LEARNING OF OBJ3

Figure 10 indicates that all membership function parameters of OBJ3 were affected after the learning phase. 


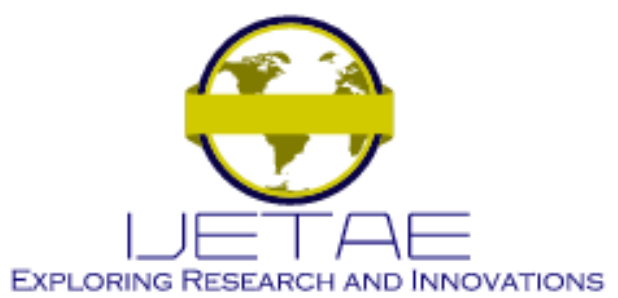

International Journal of Emerging Technology and Advanced Engineering

Website: www.ijetae.com (E-ISSN 2250-2459, Scopus Indexed, ISO 9001:2008 Certified Journal, Volume 11, Issue 11, November 2021)

This result depends on the selected initial parameters of membership functions. In fact, they can disrupt the stabilization of the system. Furthermore, it is also notable that the obtained error after 20 iterations, before and after learning, is less than or equal to $0,510^{-4}$.
Furthermore, the error after learning converges faster than that before learning. This error is used as an indicator to highlight the importance of NFHH to link the real system behaviour to the proposed Neuro-Fuzzy structure.

TABLE II

PAPERS LEARNING MODELS FOR OBJ3

\begin{tabular}{|c|c|c|c|c|c|c|c|}
\hline Iteration $^{\circ}{ }^{\circ}$ & \multicolumn{2}{|c|}{ Indicators } & Objective & $\mathbf{N}^{\circ}$ & \multicolumn{2}{|c|}{ Indicators } & Objective \\
\hline \multirow{4}{*}{1} & IP31 & 0.01 & \multirow{4}{*}{0.247} & \multirow{4}{*}{11} & IP31 & 0.02 & \multirow{4}{*}{0.141} \\
\hline & IP32 & 0.87 & & & IP32 & 0.5 & \\
\hline & IP33 & 0.066 & & & IP33 & 0.035 & \\
\hline & IP34 & 0.043 & & & IP34 & 0.011 & \\
\hline \multirow{4}{*}{2} & IP31 & 0.01 & \multirow{4}{*}{0.218} & \multirow{4}{*}{12} & IP31 & 0.02 & \multirow{4}{*}{0.114} \\
\hline & IP32 & 0.81 & & & IP32 & 0.39 & \\
\hline & IP33 & 0.026 & & & IP33 & 0.025 & \\
\hline & IP34 & 0.026 & & & IP34 & 0.022 & \\
\hline \multirow{4}{*}{3} & IP31 & 0.01 & \multirow{4}{*}{0.221} & \multirow{4}{*}{13} & IP31 & 0.02 & \multirow{4}{*}{0.107} \\
\hline & IP32 & 0.82 & & & IP32 & 0.35 & \\
\hline & IP33 & 0.043 & & & IP33 & 0.03 & \\
\hline & IP34 & 0.013 & & & IP34 & 0.028 & \\
\hline \multirow{4}{*}{4} & IP31 & 0.04 & \multirow{4}{*}{0.213} & \multirow{4}{*}{14} & IP31 & 0.009 & \multirow{4}{*}{0.096} \\
\hline & IP32 & 0.72 & & & IP32 & 0.35 & \\
\hline & IP33 & 0.063 & & & IP33 & 0.014 & \\
\hline & IP34 & 0.031 & & & IP34 & 0.011 & \\
\hline \multirow{4}{*}{5} & IP31 & 0.02 & \multirow{4}{*}{0.192} & \multirow{4}{*}{15} & IP31 & 0.01 & \multirow{4}{*}{0.086} \\
\hline & IP32 & 0.72 & & & IP32 & 0.25 & \\
\hline & IP33 & 0.022 & & & IP33 & 0.044 & \\
\hline & IP34 & 0.008 & & & IP34 & 0.04 & \\
\hline \multirow{4}{*}{6} & IP31 & 0.02 & \multirow{4}{*}{0.180} & \multirow{4}{*}{16} & IP31 & 0.02 & \\
\hline & IP32 & 0.66 & & & IP32 & 0.2 & ( \\
\hline & IP33 & 0.031 & & & IP33 & 0.05 & 0.074 \\
\hline & IP34 & 0.012 & & & IP34 & 0.026 & \\
\hline & IP31 & 0.04 & & & IP31 & 0.01 & \\
\hline & IP32 & 0.65 & 0184 & 17 & IP32 & 0.2 & \\
\hline 7 & IP33 & 0.029 & 0.184 & 17 & IP33 & 0.043 & 0.066 \\
\hline & IP34 & 0.019 & & & IP34 & $\begin{array}{l}0.075 \\
0.011\end{array}$ & \\
\hline & IP31 & 0.04 & & & IP31 & 0.01 & \\
\hline 8 & IP32 & 0.57 & 0175 & 18 & IP32 & 0.15 & 0053 \\
\hline 8 & IP33 & 0.049 & 0.175 & 18 & IP33 & 0.031 & 0.053 \\
\hline & IP34 & 0.041 & & & IP34 & 0.021 & \\
\hline & IP31 & 0.03 & & & IP31 & 0.01 & \\
\hline & IP32 & 0.49 & & & IP32 & 0.15 & \\
\hline 9 & IP33 & 0.031 & 0.173 & 19 & IP33 & 0.031 & 0.053 \\
\hline & IP34 & 0.014 & & & IP34 & 0.021 & \\
\hline & IP31 & 0.03 & & & IP31 & 0.01 & \\
\hline & IP32 & 0.49 & & & IP32 & 0.15 & \\
\hline 10 & IP33 & 0.037 & 0.144 & 20 & IP33 & 0.031 & 0.053 \\
\hline & IP34 & 0.021 & & & IP34 & 0.021 & \\
\hline
\end{tabular}




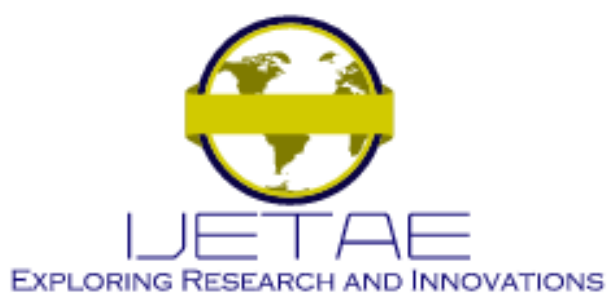

International Journal of Emerging Technology and Advanced Engineering

Website: www.ijetae.com (E-ISSN 2250-2459, Scopus Indexed, ISO 9001:2008 Certified Journal, Volume 11, Issue 11, November 2021)

In addition, we have represented in Figure 10 the corresponding membership functions before and after learning of $\mathrm{OBJ} 3$.

\section{COMPARATIVE STUDY}

The comparative study between NFHH, NN and ANFIS has been made to highlight the best NFHH performance including accuracy and number of parameters. All of them are applied to ensure the effectiveness and efficiency of the QMS [21-22-23].By keeping the same number of neurons, the identification of the parameters number and the computing of the mean square error are assessed.

The choice of determining the number of parameters for neural systems or fuzzy systems is very interesting. Indeed, if the parameter number increases then the connections number, the computing time and the rules number increase and therefore the risk of rules explosion and transforming the decisional system in a lengthy process.

Table III shows the different equations for calculating the parameters number of each model.

TABLE III

NFHH, ANFIS AND NN PARAMETERS NUMBER.

\begin{tabular}{|l|l|l|}
\hline Models & \multicolumn{2}{|c|}{ Number of parameters } \\
\hline NFHH & $\sum_{\mathrm{p}=1}^{\mathrm{p}} 2^{\mathrm{m}_{z}}+(\mathrm{P}+\mathrm{Z}+1) * \mathrm{H}+(\mathrm{H}+1)$ & $(28)$ \\
\hline ANFIS & $\sum_{\mathrm{p}=1}^{\mathrm{p}} 3^{\mathrm{m}_{z}}+(\mathrm{P}+\mathrm{Z}+1) * \mathrm{H}+(\mathrm{H}+1)$ & (29) \\
\hline NN & $\left(\sum_{\mathrm{p}=1}^{\mathrm{p}}\left(\mathrm{m}_{\mathrm{p}}+\mathrm{Z}+1\right)\right) * \mathrm{H}+(\mathrm{H}+1)$ & (30) \\
\hline
\end{tabular}

Where $\mathrm{H}$ is the entire neurons number, $\mathrm{P}$ is the lower level measures objectives index, $\mathrm{Z}$ is the upper level number of input variables and $m_{p}$ is the input number for $\mathrm{p}^{\text {th }}$ objective. For a fixed number of neurons at 10 and 20, Table IV summarizes the results of a comparative study between NFHH, ANFIS and NN for the same number of neurons.
TABLE IV

COMPARATIVE STUDY BETWEEN NFHH, ANFIS AND NN.

\begin{tabular}{|c|c|c|c|c|}
\hline Approach & $\begin{array}{l}\text { Neurons } \\
\text { number }\end{array}$ & $\begin{array}{l}\text { Parameters } \\
\text { Number }\end{array}$ & $\begin{array}{l}\text { Learning } \\
\text { rate }\end{array}$ & $\begin{array}{l}\text { Average } \\
\text { error }\end{array}$ \\
\hline \multirow{6}{*}{ NFHH } & \multirow{3}{*}{10} & \multirow{3}{*}{139} & 0.005 & 0.02168 \\
\hline & & & 0.01 & 0.02471 \\
\hline & & & 0.02 & 0.02799 \\
\hline & \multirow{3}{*}{20} & \multirow{3}{*}{209} & 0.005 & 0.02250 \\
\hline & & & 0.01 & 0.02542 \\
\hline & & & 0.02 & 0.02901 \\
\hline \multirow{6}{*}{ ANFIS } & \multirow{3}{*}{10} & \multirow{3}{*}{482} & 0.005 & 0.02933 \\
\hline & & & 0.01 & 0.03211 \\
\hline & & & 0.02 & 0.03755 \\
\hline & \multirow{3}{*}{20} & \multirow{3}{*}{552} & 0.005 & 0.03087 \\
\hline & & & 0.01 & 0.03569 \\
\hline & & & 0.02 & 0.04026 \\
\hline \multirow{6}{*}{$\mathrm{NN}$} & \multirow{3}{*}{10} & \multirow{3}{*}{171} & 0.005 & 0.07883 \\
\hline & & & 0.01 & 0.08124 \\
\hline & & & 0.02 & 0.08734 \\
\hline & \multirow{3}{*}{20} & \multirow{3}{*}{341} & 0.005 & 0.07905 \\
\hline & & & 0.01 & 0.08767 \\
\hline & & & 0.02 & 0.09173 \\
\hline
\end{tabular}

It is deduced that for the same number of neurons, NFHH can effectively reduce the number of hidden parameters. In fact, its hidden parameters (calculated by equation (28) are less than those of ANFIS and NN (calculated by equations (29) and (30). For example, NFHH requests 139 parameters for 10 neurons. However, ANFIS (482) and NN (171) demand more for the same number of neurons. Moreover, by keeping the same neurons number and modifying the learning rate values, NFHH achieves the best accuracy. For instance, by maintaining 10 neurons and 0.005 as the learning rate value, NFHH, ANFIS and NN acquire the following errors (0.02168 and 0.02933 and 0.07883), respectively. For 20 neurons, NFHH and ANFIS get an error of 0.02250 and 0.03087 , while $\mathrm{NN}$ has an error of 0.07905 . Therefore, it is notable that NFHH achieves the better accuracy by comparing its obtained rate with the desired one. Figure 11 illustrates the achievement evolution of the main objective rate ("Ensure the improvement of the system and objectives"), on one year, by applying the three different approaches (NFHH, ANFIS and NN). 


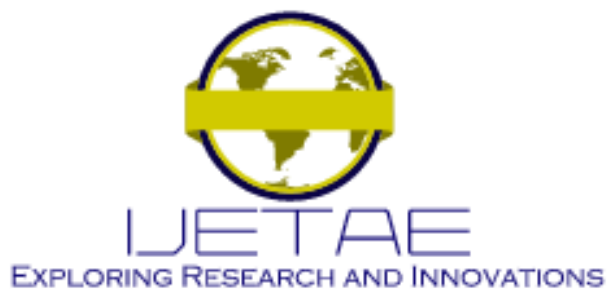

International Journal of Emerging Technology and Advanced Engineering Website: www.ijetae.com (E-ISSN 2250-2459, Scopus Indexed, ISO 9001:2008 Certified Journal, Volume 11, Issue 11, November 2021)

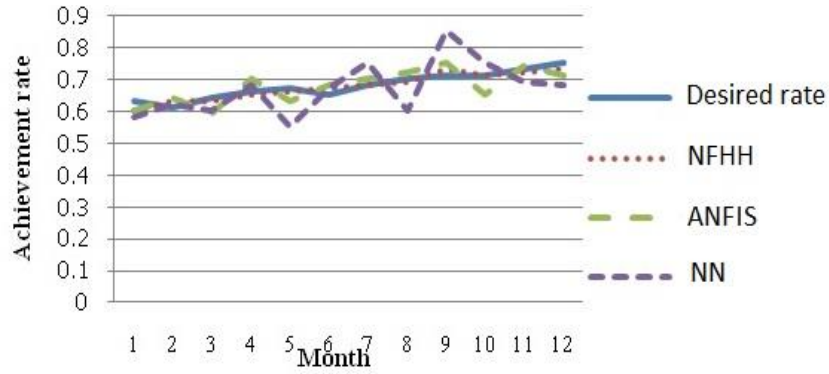

FIGURE 11. THE ACHIEVEMENT RATE EVOLUTION BY USING NFHH, ANFIS AND NN

This comparative study reveals that NFHH outperforms NN and ANFIS regarding accuracy and parameters number. Furthermore, NFHH reaches an achievement rate in the interval $[0.6,0.74]$ which surrounds the required realization rate $[0.61,0.73]$. However, the realization rate obtained by applying ANFIS [0.59, 0.75] and NN [0.58, 0.85] are less important.

\section{CONCLUSIONS}

In this paper, two approaches are investigated for a QMS control issue. They are Hierarchical Fuzzy Signature (HFS) and Neuro-Fuzzy Hierarchical Hybrid system (NFHH), respectively. Both of them are applied to ensure the effectiveness and the efficiency of companies' QMS. HFS was used to treat the case of an industrial company. Its hierarchical structure is able to treat fuzzy variables. Therefore, it reduces the complexity of the number and meta-levels of inputs and outputs. However, the NFHH approach consists of lower and upper levels. It is capable of dealing with heterogeneous variables such as quantitative and qualitative inputs. These inputs are optimized by a learning gradient algorithm and treated by the two levels.

In this study, it is deduced that NFHH has better performance over ANFIS and NN. NFHH reaches an effective accuracy, uses fewer parameters and also reduces the number of neurons. It also keeps the universal approximated property of neural and fuzzy systems.

This research leads to many perspectives such as the selection and the optimization of the number of input indicators, fuzzy rule number and membership functions. It is recommended to apply the metaheuristics algorithms, especially the genetic algorithms (GA). The hybrid network between the GA and the NFHH is mainly suggested to get the relevant number of performance indicators inputs, to reach a minimum set of membership functions and rules without knowing the topology of the overall fuzzy system.

\section{REFERENCES}

[1] Shakouri G, H., and Y. Tavassoli N. "Implementation of a hybrid fuzzy system as a decision support process: A FAHP-FMCDM-FIS composition." Expert Systems with Applications 39.3 (2012): 36823691.

[2] Lu, Jun-Jen, Hsuan-Han Huang, and Hwai-Pwu Chou. "Evaluation of an FPGA-based fuzzy logic control of feed-water for ABWR under automatic power regulating." Progress in Nuclear Energy 79 (2015): 22-31.

[3] Lu, Jun-Jen, Hsuan-Han Huang, and Hwai-Pwu Chou. "Evaluation of an FPGA-based fuzzy logic control of feed-water for ABWR under automatic power regulating." Progress in Nuclear Energy 79 (2015): 22-31.

[4] Hwang, Kuo-An, and Chia-Hao Yang. "Attentiveness assessment in learning based on fuzzy logic analysis." Expert Systems with Applications 36.3 (2009): 6261-6265.

[5] Chung, Chao-Chin, Ho-Hsien Chen, and Ching-Hua Ting. "Fuzzy logic for accurate control of heating temperature and duration in canned food sterilisation." Engineering in agriculture, environment and food 9.2 (2016): 187-194.

[6] Amza, CatalinGheorghe, and Dumitru Titi Cicic. "Industrial image processing using fuzzy-logic." Procedia Engineering 100 (2015): 492-498.

[7] Uzoka, Faith-Michael Emeka, et al. "An experimental comparison of fuzzy logic and analytic hierarchy process for medical decision support systems." Computer Methods and Programs in Biomedicine 103.1 (2011): 10-27.

[8] Bajpai, Shailendra, Anish Sachdeva, and J. P. Gupta. "Security risk assessment: Applying the concepts of fuzzy logic." Journal of Hazardous Materials 173.1-3 (2010): 258-264.

[9] Wong, Kok Wai, et al. "Hierarchical fuzzy signature structure for complex structured data." Proceedings of ISCIII 2003 International Symposium on Computational Intelligence and Intelligent Informatics. 2003.

[10] Quteishat, Anas, and Chee Peng Lim. "A modified fuzzy min-max neural network with rule extraction and its application to fault detection and classification." Applied Soft Computing 8.2 (2008): 985-995

[11] Eslamloueyan, Reza. "Designing a hierarchical neural network based on fuzzy clustering for fault diagnosis of the Tennessee-Eastman process." Applied soft computing 11.1 (2011): 1407-1415.

[12] Tang, Yu-Cheng. "An approach to budget allocation for an aerospace company-Fuzzy analytic hierarchy process and artificial neural network." Neurocomputing 72.16-18 (2009): 3477-3489.

[13] Brennand, Kristen J., Melissa A. Landek-Salgado, and Akira Sawa. "Modeling heterogeneous patients with a clinical diagnosis of schizophrenia with induced pluripotent stem cells." Biological psychiatry 75.12 (2014): 936-944.

[14] Petković, Dalibor, ŽarkoĆojbašić, and StevoLukić. "Adaptive neuro fuzzy selection of heart rate variability parameters affected by autonomic nervous system." Expert Systems with Applications 40.11 (2013): 4490-4495.

[15] Im, Byoung-Mo, et al. "Declustering signature files based on a dynamic measure." Information processing letters 74.5-6 (2000): 235-241. 


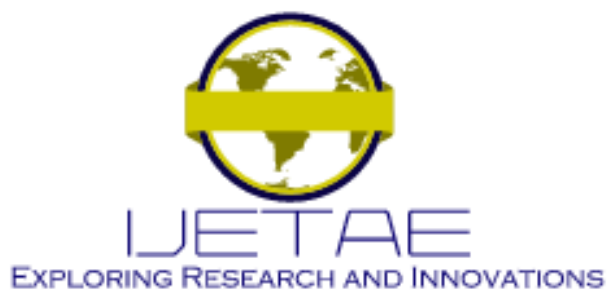

International Journal of Emerging Technology and Advanced Engineering

Website: www.ijetae.com (E-ISSN 2250-2459, Scopus Indexed, ISO 9001:2008 Certified Journal, Volume 11, Issue 11, November 2021)

[16] Pharow, Peter, and Bernd Blobel. "Electronic signatures for longlasting storage purposes in electronic archives." International Journal of Medical Informatics 74.2-4 (2005): 279-287.

[17] Mead, Steve. "Unique file identification in the national software reference library." Digital Investigation 3.3 (2006): 138-150.

[18] Chang, Ye-In, et al. "An efficient signature-based strategy for supporting inexact filtering in information filtering systems." Expert Systems with Applications 36.4 (2009): 8431-8442.

[19] Wong, Kok Wai, TamásGedeon, and László Kóczy. "Construction of fuzzy signature from data: an example of SARS pre-clinical diagnosis system." 2004 IEEE International Conference on Fuzzy Systems (IEEE Cat. No. 04CH37542). Vol. 3. IEEE, 2004.
[20] Mahmoud, Hajer Ben, et al. "A Multi Agent Hierarchial Fuzzy Signatures Approach To Optimize A Quality Management System." I-manager's Journal on Software Engineering 4.4 (2010): 1.

[21] Dammak, Hajer Ben Mahmoud, et al. "Fuzzy-Neural Networks for a piloted Quality Management System." 2012 16th IEEE Mediterranean Electrotechnical Conference. IEEE, 2012.

[22] Mahmoud, Hajer Ben, et al. "Comparative study of Fuzzy Hierarchical Hybrid approaches for control of Quality Management System." 2015 International Conference on Industrial Engineering and Systems Management (IESM). IEEE, 2015.

[23] Wang, Di, Xiao-Jun Zeng, and John A. Keane. "Hierarchical hybrid fuzzy-neural networks for approximation with mixed input variables." Neurocomputing 70.16-18 (2007): 3019-3033. 